\title{
Tumor necrosis factor $\alpha$ induces epithelial-mesenchymal transition and promotes metastasis via $N F-\kappa B$ signaling pathway-mediated TWIST expression in hypopharyngeal cancer
}

\author{
LIANG YU, YAKUI MU, NA SA, HAIBO WANG and WEI XU \\ Department of Otolaryngology - Head and Neck Surgery, Provincial Hospital Affiliated to \\ Shandong University, Jinan, Shandong 250021, P.R. China \\ Received September 9, 2013; Accepted October 14, 2013
}

DOI: $10.3892 /$ or.2013.2841

\begin{abstract}
Epithelial-mesenchymal transition (EMT) is an important mechanism in cancer metastasis. Tumor necrosis factor $\alpha(\mathrm{TNF} \alpha)$ can induce cancer invasion and metastasis associated with EMT. However, the underlying mechanisms are not entirely clear. Therefore, we investigated whether TNF $\alpha$ has an effect on EMT and invasion and metastasis in human hypopharyngeal cancer FaDu cells, and further explored the potential mechanisms. In the present study, we demonstrated that TNF $\alpha$ induced EMT in FaDu cells and promoted FaDu cell migration and invasion. TNF $\alpha$-induced EMT was characterized by a change from well organized cell-cell adhesion and cell polarity to loss of cell-cell contacts, cell scattering and increased expression of vimentin and N-cadherin accompanied by a decrease in E-cadherin. Furthermore, we found that p65 translocated to the nucleus after TNF $\alpha$ stimulation and increased the nuclear expression of TWIST. We demonstrated that TNF $\alpha$ treatment also increased the expression of TWIST by activating the $\mathrm{NF}-\kappa \mathrm{B}$ signaling pathway. While p65 was inhibited by siRNA-65 or BAY11-7082 (inhibitor of NF- $\kappa \mathrm{B})$, TWIST expression was also decreased. Therefore, we conclude that TNF $\alpha$ induces EMT and promotes metastasis via $N F-\kappa B$ signaling pathway-mediated TWIST expression in hypopharyngeal cancer.
\end{abstract}

\section{Introduction}

The development of cancer is often associated with chronic inflammation, which suggests a strong relationship between

Correspondence to: Professor Wei Xu or Professor Haibo Wang, Department of Otolaryngology - Head and Neck Surgery, Provincial Hospital Affiliated to Shandong University, Jinan, Shandong 250021, P.R. China

E-mail: xuwhns@126.com

E-mail: whbotologic797@163.com

Key words: tumor necrosis factor $\alpha$, epithelial-mesenchymal transition, NF- $\mathrm{KB}$, TWIST, hypopharyngeal cancer, tumor microenvironment inflammation and tumorigenesis (1). Tumor necrosis factor $\alpha$ $(\mathrm{TNF} \alpha)$ is one of the key inflammatory mediators involved in inflammation-associated cancer (2). Although over the last few decades, a high dose of TNF $\alpha$ has been used as a cytotoxic agent, recent reports support the link between chronic low-level TNF $\alpha$ exposure and the acquisition of certain malignant phenotypes, such as increased growth, invasion and metastasis (2). In addition, TNFo is an important activator of the canonical $\mathrm{NF}-\kappa \mathrm{B}$ pathway. Upon stimulation, activated IKK- $\beta$ phosphorylates the NF- $\kappa \mathrm{B}$ inhibitor, I $\mathrm{B} \alpha$, and triggers its rapid degradation resulting in the liberation of $N F-\kappa B$. As a consequence, the $\mathrm{NF}-\kappa \mathrm{B}$ heterodimer translocates to the nucleus, binds to its cognate DNA motifs in the promoters, and induces expression of a myriad of genes implicated in the immune response, cell proliferation, angiogenesis, cell survival and invasion $(3,4)$.

Epithelial-mesenchymal transition (EMT), which is a complex reprogramming process of epithelial cells, plays an important role in tumor invasion and metastasis (5). EMT is characterized as the morphologic alteration from an epithelial to a mesenchymal phenotype, including loss of epithelial cell markers, such as E-cadherin, $\alpha$-catenin and $\gamma$-catenin, and a gain in mesenchymal components, such as vimentin, $\mathrm{N}$-cadherin and fibronectin (6,7). In addition, studies show that a group of transcriptional factors regulate EMT, such as TWIST, Snail and Slug. Previous studies demonstrate that TWIST is implicated in metastasis by regulating EMT in HNSCC $(8,9)$. Recent reports indicate that TNF $\alpha$ induces EMT via AKT/GSK or NF- $\kappa \mathrm{B}-$ mediated expression of Snail and TWIST in breast, renal and colon cancer (10-13). Collectively, the evidence suggests that $\mathrm{TNF} \alpha$ may regulate the critical processes of tumor promotion and progression, including angiogenesis, oncogene activation and EMT.

Hypopharyngeal cancer is one of the most common head and neck squamous cell carcinomas (HNSCCs). More than $75 \%$ of patients with hypopharyngeal cancer are at an advanced stage at the time of diagnosis (14). Lymph node metastasis is present in $60-80 \%$ of patients and it directly affects the prognosis of this disease (15). Metastasis of tumors is a complex process, and various factors are involved in each step of metastasis (16). Thus, in the present study, we investigated whether TNF $\alpha$ induces EMT via an increase in TWIST 


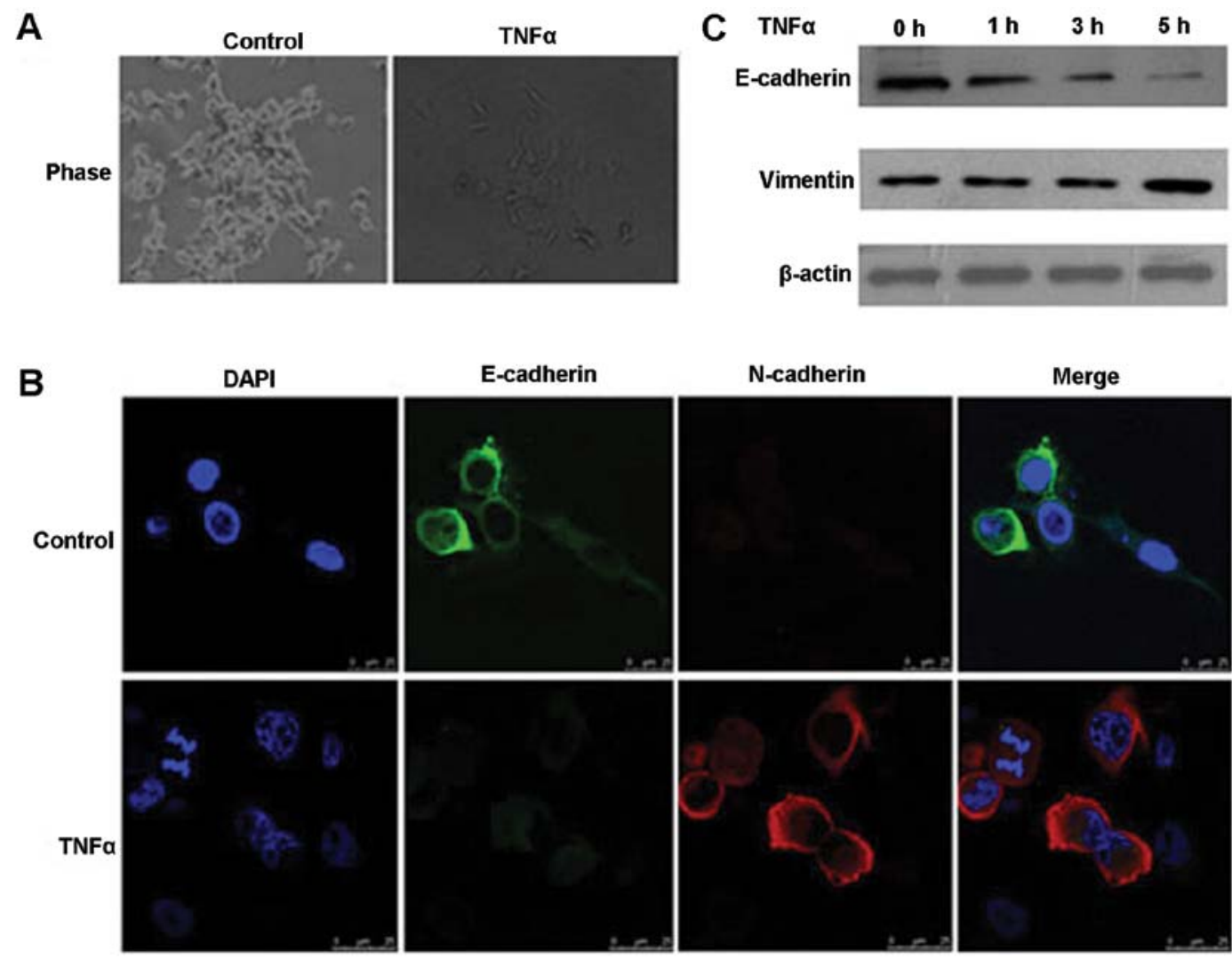

Figure 1. TNF $\alpha$ induces epithelial-mesenchymal transition. (A) TNF $\alpha(10 \mathrm{ng} / \mathrm{ml})$ altered the morphology of FaDu cells as detected by reserved microscopy (x200 magnification). The morphology of the FaDu cells following treatment of TNF $\alpha(10 \mathrm{ng} / \mathrm{ml})$ was altered from well organized cell-cell adhesion and cell polarity to loss of cell-cell contacts and cell scattering. (B) Immunofluorescence micrographs show the expression of EMT markers in FaDu cells following the treatment of $\mathrm{TNF} \alpha(10 \mathrm{ng} / \mathrm{ml})$. FaDu cells were treated with $\mathrm{TNF} \alpha$ for $5 \mathrm{~h}$. After fixation, the epithelial marker E-cadherin (green) and mesenchymal marker $\mathrm{N}$-cadherin (red) were analyzed by confocal microscopy. Cell nuclei were stained with DAPI (blue). (C) Western blot analysis of the protein expression of the EMT markers. FaDu cells were treated with TNF $\alpha$ at different time points $(0,1,3,5 \mathrm{~h})$. Epithelial marker E-cadherin was downregulated, whereas expression of mesenchymal marker vimentin was upregulated. TNF $\alpha$, tumor necrosis factor $\alpha$; EMT, epithelial-mesenchymal transition.

expression in human hypopharyngeal cancer FaDu cells and thereby promotes FaDu cell metastasis. Next, we aimed to ascertain whether the $\mathrm{NF}-\kappa \mathrm{B}$ signaling pathway is activated and regulates TNF $\alpha$-induced TWIST expression.

\section{Materials and methods}

Materials. Commercially available antibodies used were as follows: NFkbp65, TWIST, E-cadherin and N-cadherin (all from Abcam, UK); vimentin, $\mathrm{p}-\mathrm{IKK}$ and $\mathrm{p}-\mathrm{I} \kappa \mathrm{B} \alpha$ (all from Cell Signaling Technology, Inc., USA); lamin B and actin (both from Santa Cruz Biotechnology, Inc., USA) and TNFa (Cell Signaling Technology, Inc.). p65siRNA(h) and Bay 11-7082 were both from Santa Cruz Biotechnology, Inc.

Cell culture and transfection. The human hypopharyngeal cancer FaDu cells were cultured in Dulbecco's modified Eagle's medium (DMEM) containing $10 \%$ fetal calf serum, $100 \mathrm{U} / \mathrm{ml}$ penicillin and $100 \mathrm{mg}$ streptomycin at $37^{\circ} \mathrm{C}$ in a humidified atmosphere composed of $95 \%$ air and $5 \% \mathrm{CO}_{2}$. Detailed experimental procedures of the cell transfection were previously described (9).

Observation of morphological changes. The morphological changes in the FaDu cells were observed using an inverted microscope. Images were captured using a Leica microscope image system (Leica, Germany).

Immunofluorescence. The cells were cultured on chamber slides, serum starved for $12 \mathrm{~h}$, then exposed to TNF $\alpha(10 \mathrm{ng} / \mathrm{ml})$ for the indicated times. Cells were washed 3 times with PBS, fixed with $4 \%$ paraformaldehyde for $20 \mathrm{~min}$ and permeabilized with $0.3 \%$ Triton X-100 for $10 \mathrm{~min}$. After blocking with bovine serum albumin for $2 \mathrm{~h}$ at room temperature, cells were incubated with antibodies against E-cadherin, N-cadherin, p65 or TWIST (1:100 dilution) at $4^{\circ} \mathrm{C}$ overnight. Slides were washed 3 times with PBS and incubated with fluorescein isothiocyanate (FITC) or tetramethylrhodamine isothiocyanate (TRITC) secondary antibodies for $1 \mathrm{~h}$ at room temperature. The nuclei were stained with 4',6-diamidine-2'-phenylindole (DAPI) for 2 min. Samples were examined using confocal microscopy (Leica, Germany) to analyze expression of E-cadherin, N-cadherin, TWIST and p65.

Western blotting. Detailed experimental procedures of western blot analysis of gene expression were previously described (17). Western blot analysis was performed with antibodies against TWIST (1:100), E-cadherin (1:200), N-cadherin (1:200), p65 $(1: 400)$, vimentin $(1: 1,000)$, p-IKK $(1: 1,000), \mathrm{p}-\mathrm{I} \kappa \mathrm{B} \alpha(1: 1,000)$, lamin $\mathrm{B}(1: 1,000)$ and $\beta$-actin $(1: 3,000)$. 

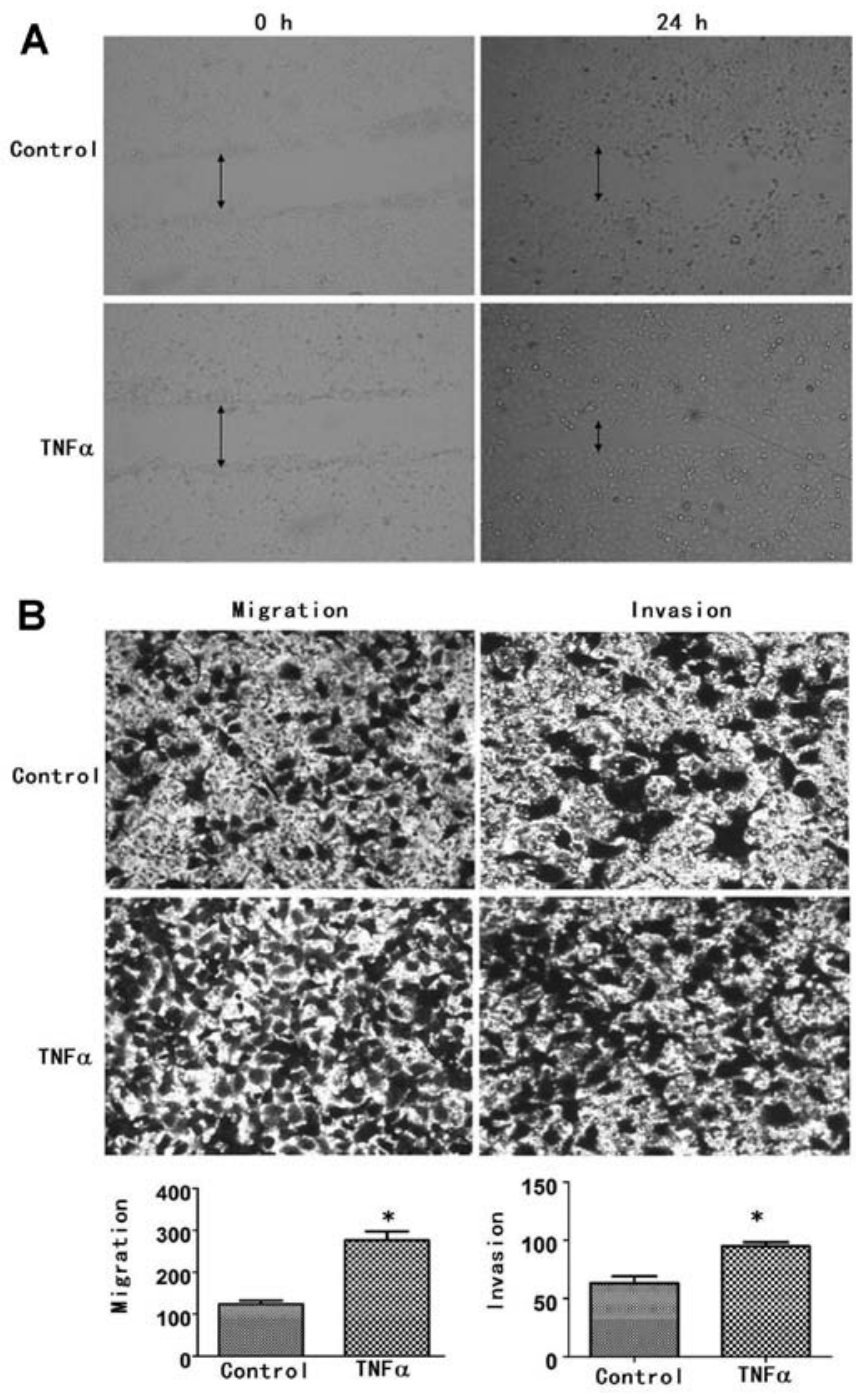

Figure 2 . TNF $\alpha$ increases cancer cell motility, migratory and invasive abilities. (A) Cell motility in FaDu cells was examined by a wound healing assay (x40 magnification). (B) Migration (left panels) and invasion (right panels) were examined by Transwell assays in the control group and the TNF $\alpha$ group, respectively (x100 magnification). All experiments were conducted 3 times. $\mathrm{TNF} \alpha$, tumor necrosis factor $\alpha$.

Wound healing assay. The FaDu cells were plated onto 6-well plates at a concentration of $5 \times 10^{5}$ cells/well, and were serum starved for $12 \mathrm{~h}$. Tumor cells were then treated with or without TNFa (10 ng/ml). Cell monolayers were carefully wounded by scratching with a sterile plastic pipette tip. The cells were then washed twice with cooled PBS before observation. For each wound, the images were captured at 0 and $24 \mathrm{~h}$ in the same fields after treatment.

Transwell chamber assay. FaDu cells were pretreated with or without TNF $\alpha(10 \mathrm{ng} / \mathrm{ml})$ for $24 \mathrm{~h}$, and $3 \times 10^{4}$ cells were plated in the upper chamber. Detailed experimental procedures of the invasion and migration assays were previously described (9).

Statistical analysis. Data are expressed as means \pm standard deviation (SD), and statistical significance was assessed by the analysis of variance test. All statistical tests employed in the present study were two-sided. P-values $<0.05$ were consid-

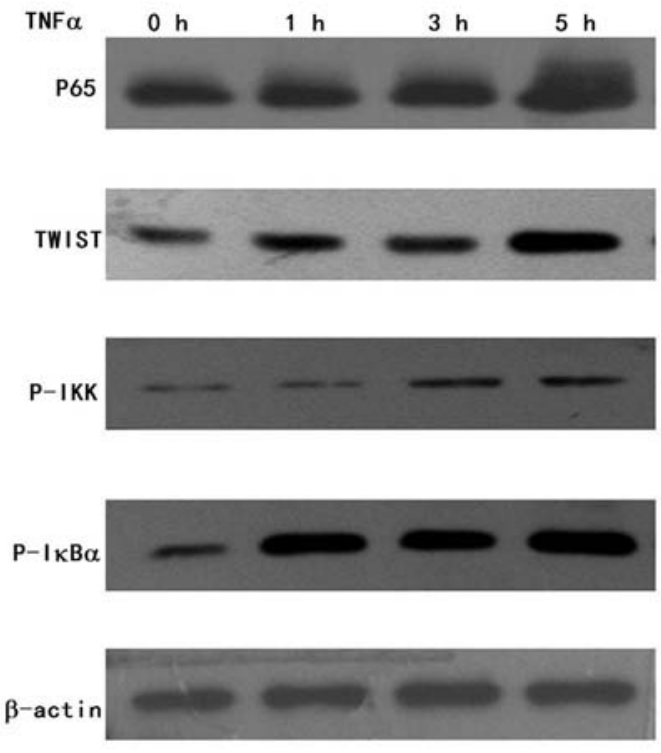

Figure 3. TNFa induces TWIST expression, and P65 expression is upregulated together with $\mathrm{TNF} \alpha$-induced TWIST expression in the FaDu cells. TWIST, P65, p-IKK and p-IкB $\alpha$ expression in the FaDu cells exposed to $\mathrm{TNF} \alpha$ was increased in a time-dependent manner $(0,1,3,5 \mathrm{~h})$ as determined by western blotting. TNF $\alpha$, tumor necrosis factor $\alpha$.

ered to indicate statistically significant results. Statistical calculations were performed using SPSS software package, version 13.0 (SPSS Inc., USA).

\section{Results}

$T N F \alpha$ induces EMT. To explore whether TNF $\alpha$ has an effect on the morphology of FaDu cells, FaDu cells were treated with TNF $\alpha(10 \mathrm{ng} / \mathrm{ml})$. We found that the morphology of the FaDu cells following treatment with TNF $\alpha$ was altered from well organized cell-cell adhesion and cell polarity to loss of cell-cell contacts and cell scattering (Fig. 1A). Cells underwent a significant change in morphology from a cobblestone morphology to exhibiting mesenchymal spindle-like features. Next, we observed the expression of EMT molecular markers using immunofluorescence and western blotting, and found that the expression of the epithelial marker E-cadherin was downregulated, whereas the mesenchymal markers, vimentin and $\mathrm{N}$-cadherin, were significantly upregulated in the $\mathrm{FaDu}$ cells (Fig. 1B and C). This phenomenon indicates that TNF $\alpha$ induces EMT in human hypopharyngeal cancer FaDu cells.

TNF $\alpha$ increases cancer cell motility, migratory and invasive abilities. To confirm that the change in morphology has an effect on the function of the cells, wound healing and Transwell chamber assays were used to measure cellular motility, migratory and invasive abilities. After $24 \mathrm{~h}$ following exposure to $\mathrm{TNF} \alpha$, the speed of motility of the FaDu cells was found to be more rapid than that of the control group; the former was closer to the center of the wound area than the control group (Fig. 2A). Promotion of migration and invasion in the FaDu cells by $\mathrm{TNF} \alpha$ was also confirmed by the Transwell chamber assay. The numbers of cells that had migrated in the control and TNF $\alpha$ treatment groups were $124 \pm 15$ and $276 \pm 38$, respectively $(\mathrm{P}<0.05)$ (Fig. $2 \mathrm{~B})$. In the in vitro invasion assay, 
A

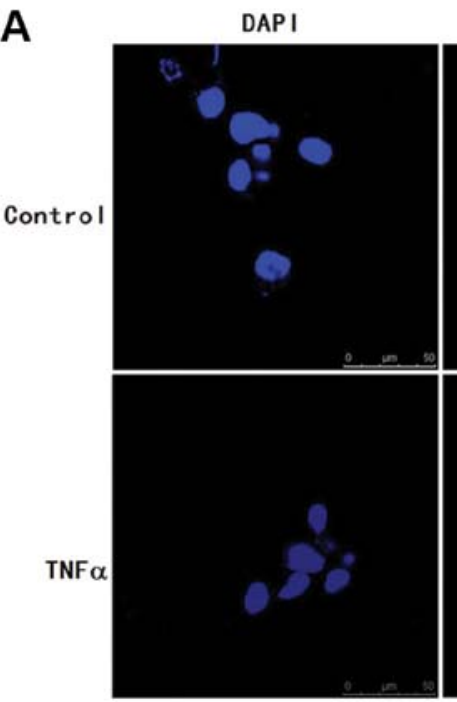

DAPI
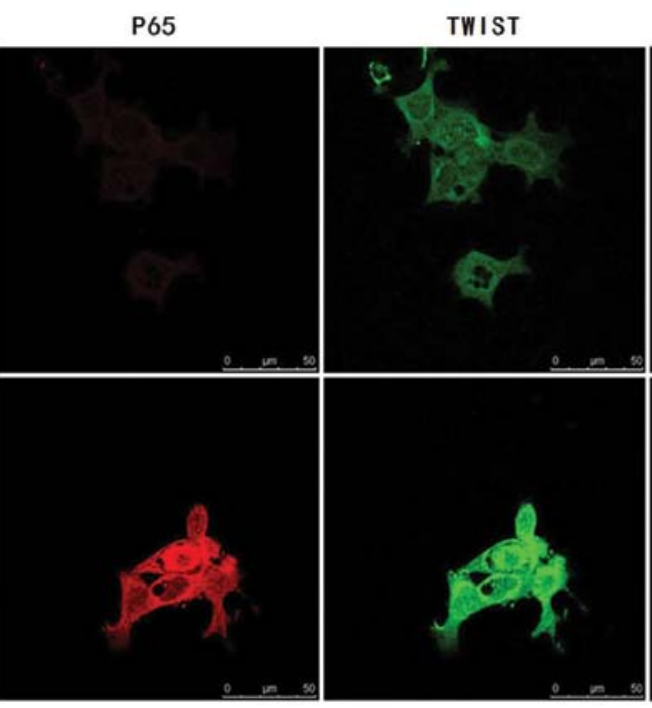

Merge

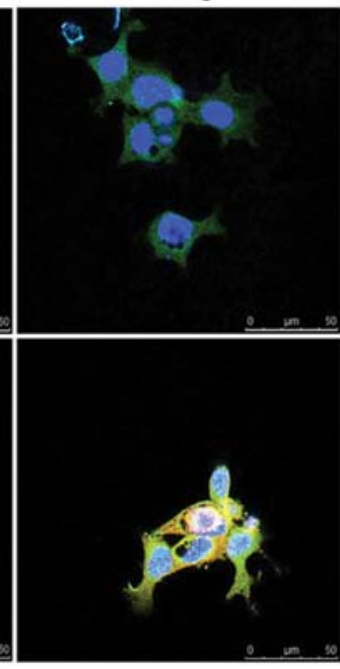

B

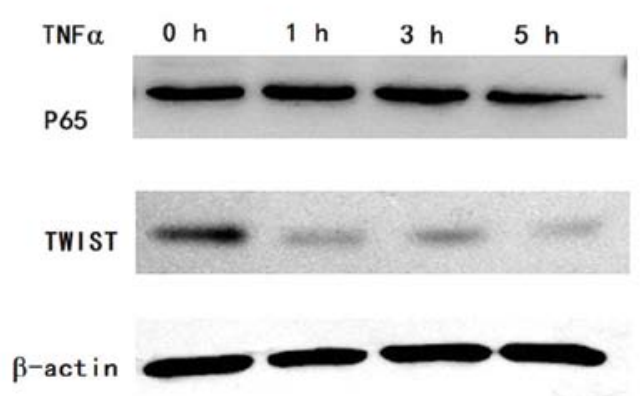

Nucleus

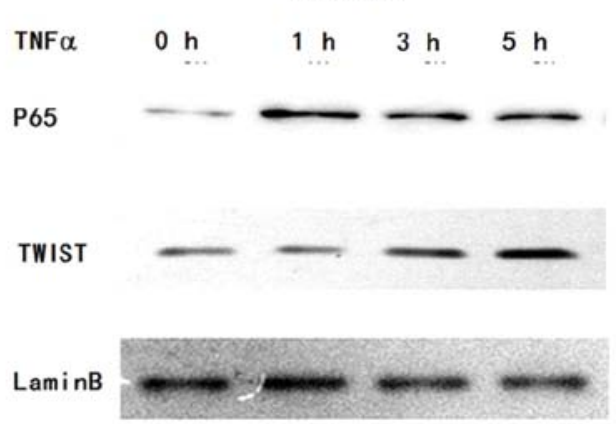

Figure 4. TNF $\alpha$ induces p65 nuclear translocation and nuclear expression of TWIST. (A) Immunofluorescence micrographs show the expression of p65 and TWIST following treatment of TNF $\alpha(10 \mathrm{ng} / \mathrm{ml})$ for $5 \mathrm{~h}$. After fixation, p65 (red) and TWIST (green) were analyzed by confocal microscopy. Cell nuclei were stained with DAPI (blue). (B) Western blot analysis of p65 and TWIST expression in FaDu cells following the treatment of TNF $\alpha$ (10 ng/ml). FaDu cells were treated with TNF $\alpha$ for different times $(0,1,3,5 \mathrm{~h})$. Cytoplasmic and nuclear p65 and TWIST protein were separated using hypotonic buffer. Lamin B and $\beta$-actin indicate the nuclear and cytoplasmic fraction, respectively. TNF $\alpha$, tumor necrosis factor $\alpha$.

we found that the number of invasive cells in the TNF $\alpha$ treatment group was $95 \pm 3$, significantly more than the number in the control group $(63 \pm 6, \mathrm{P}<0.05)$ (Fig. 2B). These results suggest that $\mathrm{TNF} \alpha$ increased cellular motility, migratory and invasive abilities in the FaDu cells.

TNF $\alpha$ induces TWIST expression in the FaDu cells. Given that TWIST plays an important role in promoting the migration and invasion of HNSCC cells by regulating EMT, we aimed to ascertain whether expression of TWIST is altered in TNF $\alpha$ induced EMT by western blotting. We found that TWIST expression was increased in a time-dependent manner in the FaDu cells following exposure to TNF $\alpha$ (Fig. 3). The results indicate that TNF $\alpha$ induces TWIST expression in the FaDu cells.

P65 expression is upregulated and translocated into the nucleus along with TNF $\alpha$-induced TWIST expression. Given that TNF $\alpha$ induces p65 activation in the canonical NF- $\kappa \mathrm{B}$ pathway, we investigated whether p65 is activated upon TNF $\alpha$-induced TWIST expression in the FaDu cells. We measured the p65 expression by western blotting, and the results showed that p65 expression following exposure to TNF $\alpha$ was increased in a time-dependent manner (Fig. 3). This suggests that P65 was upregulated together with TNF $\alpha$-induced TWIST expression in the FaDu cells. To further elucidate how TNF $\alpha$ induces p65 activation upon TNF $\alpha$-induced TWIST expression, we examined p-IKK and $\mathrm{p}-\mathrm{I} \kappa \mathrm{B} \alpha$ expression. Western blot analysis showed that $\mathrm{p}$-IKK and $\mathrm{p}-\mathrm{I} \kappa \mathrm{B} \alpha$ expression was increased in the $\mathrm{TNF} \alpha$-activated p65-expressing cells, respectively (Fig. 3). Next, we tested the nuclear p65 and TWIST expression by immunofluorescence. Compared to the control group, we observed that the levels of nuclear p65 and TWIST were increased in the TNF $\alpha$ treatment group (Fig. 4A). To further confirm the upregulation of nuclear TWIST and p65 expression, cytoplasmic and nuclear fractions in the FaDu cells were isolated upon treatment with $\mathrm{TNF} \alpha$. We also observed that TNF $\alpha$-induced nuclear expression of p65 and TWIST was significantly increased by western blotting (Fig. 4B). These results suggest that TNF $\alpha$ activates P65 expression and triggers a dynamic interaction between nuclear translocation of p65 and nuclear expression of TWIST. 
A

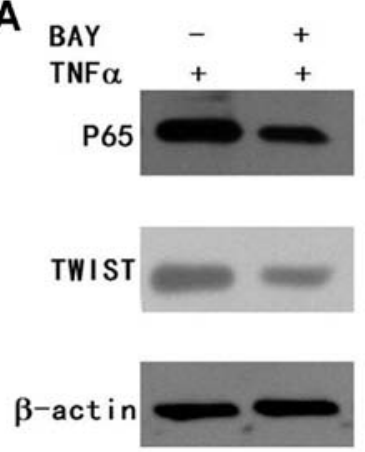

B

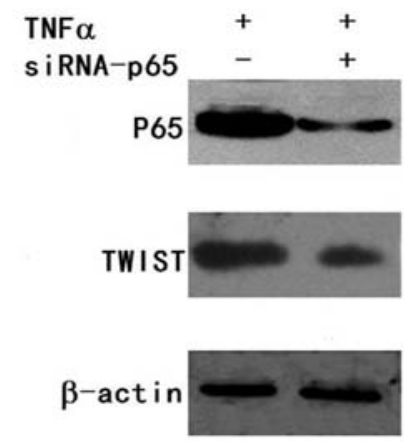

Figure 5. Downregulation of p65 expression inhibits TNF $\alpha$-induced TWIST expression in FaDu cells. (A) FaDu cells were pretreated with NF-kB inhibitor (BAY11-7082) for $2 \mathrm{~h}$ before TNF $\alpha$ stimulation, and FaDu cells were then treated with TNF $\alpha$ for $5 \mathrm{~h}$. p65 and TWIST expression was determined by western blotting. The results showed that BAY11-7082 inhibited p65 expression and blocked TNF $\alpha$-induced TWIST expression. (B) siRNA-p65 was transfected into the FaDu cells that were treated with TNF $\alpha$ for $5 \mathrm{~h}$. The transfected cells were incubated for $24 \mathrm{~h}$ and used for analysis by western blotting. p65 expression was decreased in the siRNA-p65 group, and TWIST expression was also decreased in the siRNA-p65 group. TNF $\alpha$, tumor necrosis factor $\alpha$.

Downregulation of p65 expression inhibits TNFa-induced TWIST expression in FaDu cells. To further explore whether the alteration of p65 expression has any effect on TNF $\alpha$-induced TWIST expression, BAY11-7082 (inhibitor of NF- $\mathrm{KB}$ ) was used. FaDu cells were pretreated with BAY11-7082 for $2 \mathrm{~h}$ before TNF $\alpha$ stimulation, and FaDu cells were then treated with TNF $\alpha$ for 5 h. p65 and TWIST expression was determined by western blotting. We found that BAY11-7082 inhibited p65 expression and blocked TNF $\alpha$-induced TWIST expression (Fig. 5A). To diminish the off-target effect of the chemical inhibitor in TNF $\alpha$-induced TWIST expression, we introduced siRNA-p65 into FaDu cells. The transfected cells were incubated for $24 \mathrm{~h}$ and used for analysis by western blotting. We found that p65 expression was decreased in the siRNA-p65 group. At the same time, TWIST expression was also decreased in the siRNA-p65 group (Fig. 5B). These results showed that silencing of p65 expression also attenuated TNF $\alpha$-induced TWIST expression.

\section{Discussion}

$\mathrm{TNF} \alpha$, a pro-inflammatory cytokine predominantly produced by macrophages, is a key molecule in the regulation of the inflammatory processes in tumor promotion. Clinically, increased expression of $\mathrm{TNF} \alpha$ is present in various preneoplastic and malignant diseases. TNF $\alpha$ has been reported to be elevated in the blood serum of patients diagnosed with advanced stage breast tumors and to be correlated with an increased number and size of metastatic sites $(18,19)$. In addition, TNF $\alpha$ is frequently detected in human cancers with poor prognosis, such as ovarian, renal and breast cancers (20). Furthermore, TNF $\alpha$ has been shown to promote the growth and invasiveness of colon and prostate cancer epithelial cells in vitro and in vivo $(18,21)$.

It is known that TNF $\alpha$ is involved in EMT and enhances transforming growth factor- $\beta 1$ (TGF $\beta$-1)-induced EMT in

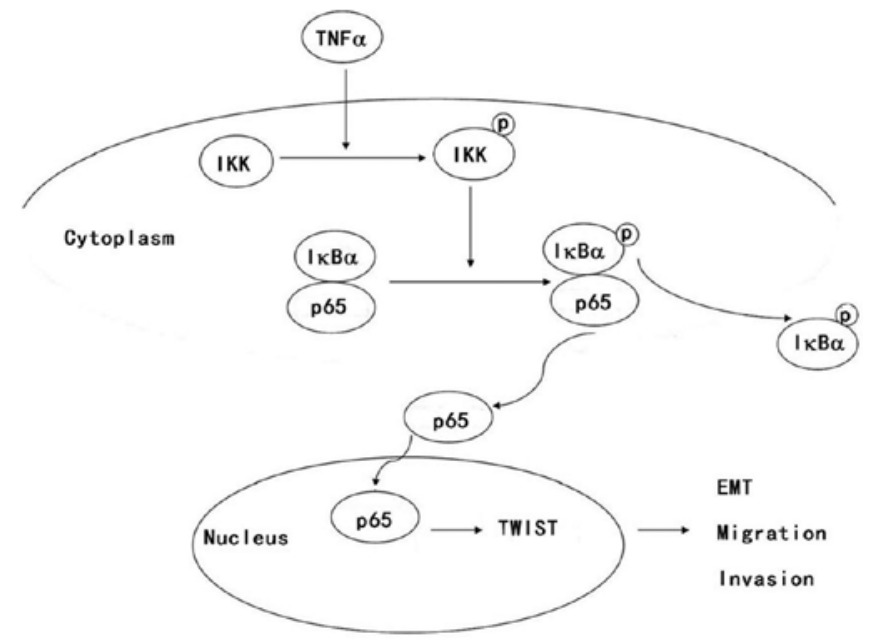

Figure 6. Schematic illustration of TNF $\alpha$-induced EMT and promotion of metastasis via $\mathrm{NF}-\kappa \mathrm{B}$ signaling pathway-mediated TWIST expression in hypopharyngeal cancer. i) IKK is activated after TNF $\alpha$ stimulation. ii) I $\mathrm{B} \alpha$ is phosphorylated, $\mathrm{NF}-\kappa \mathrm{B}(\mathrm{p} 65)$ dissociates from $\mathrm{I} \kappa \mathrm{B} \alpha$ and is translocated to the cell nucleus. iii) Nuclear NF- $\mathrm{B}$ (p65) binds to its target gene TWIST, which is involved in EMT, migration, invasion and tumor growth. TNFa, tumor necrosis factor $\alpha$; EMT, epithelial-mesenchymal transition.

multiple cancer cell types (18). EMT is an important step during primary tumor metastasis. Although increasing evidence indicates that TNF $\alpha$ induces EMT and promotes cancer migration and invasion $(19,22)$, the effect of TNF $\alpha$ on HNSCC remains undetermined.

In the present study, we found that TNF $\alpha$ induced morphological alterations in FaDu cells, and their morphology switched from a tightly packed growth pattern to scattered and fibroblast-like colonies. At the same time, we found that expression of the epithelial marker E-cadherin was downregulated, whereas that of mesenchymal markers vimentin and $\mathrm{N}$-cadherin was significantly upregulated. These results indicate that $\mathrm{TNF} \alpha$ induces EMT.

The most distinguished characteristic of EMT is the morphologic alteration from an epithelial to a mesenchymal phenotype, which is often accompanied by the dissolution of epithelial tight junctions, loss of cellular adhesion, downregulation of the expression of various epithelial markers, but acquired expression of mesenchymal components, resulting in loss of cell polarity, cell-basement adhesion, and cell-cell contact and the acquisition of migratory and invasive abilities (7). When epithelial cells undergo EMT, which is thought to contribute to the invasive ability of cancer cells (5), EMT and its accompanying reduction in E-cadherin expression have been shown to be essential for the extravasation of cancer cells into secondary organs (23). Thus, we aimed to ascertain whether TNF $\alpha$-induced EMT has an effect on HNSCC cell motility, migratory and invasive abilities. We found that $\mathrm{TNF} \alpha$ increased cellular motility, migratory and invasive abilities.

TWIST, is known as an essential regulator of the aggressive phenotype of EMT (24). Once TWIST is activated, it recruits histone deacetylases to the E-box elements within the E-cadherin promoter, resulting in transcriptional silencing of E-cadherin expression and increased motility, migration and 
invasion $(24,25)$. Our previous research confirmed that alteration of TWIST affects EMT in HNSCC cells, and knockdown of TWIST inhibits cell migration, invasion and formation of the EMT phenotype in HNSCC and breast cancer cells $(8,9,26)$. Thus, we hypothesized that TWIST may be implicated in TNF $\alpha$-induced EMT in HNSCC cells. Indeed, the present study showed that expression of TWIST was significantly elevated in TNF $\alpha$-induced EMT. The results indicate that TNF $\alpha$ induced EMT by mediating TWIST expression consequently increasing cell motility, migration and invasion.

$\mathrm{TNF} \alpha$ is one of the most important pro-inflammatory cytokines produced in the tumor microenvironment. Several lines of evidence demonstrate that TNF $\alpha$ and/or the NF- $\mathrm{KB}$ signaling pathway plays a key role in the regulation of EMT (26). The contribution of NF- $\mathrm{kB}$ signaling to the initiation and progression of cancer is clearly documented (26-28). NF- $\kappa B$ is composed of 5 subunits, including RELA (p65), RELB, c-REL, NF- $\kappa B 1$ (p105/p50) and NF- $\mathrm{kB} 2$ (p100/p52). P65 expression activation reflects activation of the NF- $\mathrm{KB}$ signaling pathway. In the canonical pathway of NF- $\mathrm{kB}$ activation, NF- $\kappa B$ activation is induced by various inflammatory stimuli, including $\mathrm{TNF} \alpha$, interleukin-1 (IL-1) and lipopolysaccharide (LPS). Upon stimulation, activated IKKb phosphorylates I $\kappa \mathrm{B} \alpha$ (NF- $\kappa \mathrm{B}$ inhibitor) and results in disso-

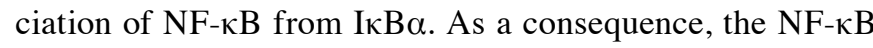
heterodimer translocates to the nucleus and activates expression of a myriad of target genes involved in cell proliferation, angiogenesis, cell survival, invasion and EMT (29).

Given that TNF $\alpha$ can activate the NF- $\mathrm{BB}$ signaling pathway and provides a mechanistic link between inflammation and cancer, we hypothesized that the NF- $\mathrm{kB}$ signaling pathway may be involved in TNF $\alpha$-induced TWIST expression. In the present study, we found that $\mathrm{p}-\mathrm{IKK}, \mathrm{p}-\mathrm{I \kappa B} \alpha$ and $\mathrm{p} 65$ expression was increased upon $\mathrm{TNF} \alpha$-induced TWIST expression. The results indicate that the canonical NF- $\mathrm{kB}$ signaling pathway was activated. Furthermore, p65 translocated to the nucleus after TNF $\alpha$ stimulation increased the nuclear expression of TWIST. The change in $\mathrm{p} 65$ expression was consistent with TWIST.

In order to further determine whether the alteration in p65 expression has an effect on TNF $\alpha$-induced TWIST expression, we analyzed and found that when p65 was inhibited by siRNA-65 or BAY11-7082, TWIST expression was also attenuated. The results indicated that the alteration in $\mathrm{p} 65$ expression affected TNF $\alpha$-induced TWIST expression. Taken together, these data revealed that the NF- $\mathrm{kB}$ signaling pathway is involved in TNF-induced EMT, and p65 activation regulates TWIST expression in TNFo-induced EMT. A recent study showed that TNF $\alpha$ induces EMT via upregulation of TWIST in breast cancer cells (26). TNF $\alpha$ can also upregulate Slug, which imparts breast cancer cells with a stem cell-like phenotype (30). Further research demonstrated that inflammation induces invasion and metastasis via NF-kB-mediated stabilization of Snail (12).

In contrast, several studies reported that EMT induced by TNF $\alpha$ requires the AKT/GSK- $3 \beta$ signaling pathway and revealed that AKT/GSK-3 $\beta$-mediated stabilization of Snail is required for TNF $\alpha$-induced EMT in colorectal cancer $(10,11)$. Thus, further investigation is warranted to determine whether TWIST cooperates with other transcriptional factors, such as
Snail and Slug regarding the regulation of $\mathrm{TNF} \alpha$-mediated EMT in FaDu cells.

In summary, we demonstrated that TNFa induces EMT via increased TWIST expression in human FaDu cells and promotes hypopharyngeal cancer migration and invasion. Furthermore, we elucidated that the NF-kB signaling pathway was activated in FaDu cells, which regulated TNFa-induced TWIST expression. The detailed mechanism is illustrated in Fig. 6. We conclude that TNF $\alpha$ induced EMT and promoted metastasis via NF- $\kappa B$ signaling pathway-mediated TWIST expression in hypopharyngeal cancer.

\section{Acknowledgements}

The present study was supported by the Shandong Provincial International Science and Technology Cooperation Project of China (no. 2010GHZ20202) and the Graduate Independent Innovation Foundation of Shandong University (GIIFSDU) (no. yzc12157).

\section{References}

1. Shacter E and Weitzman SA: Chronic inflammation and cancer. Oncology 16: 217-226, 229, 2002.

2. Balkwill F: Tumour necrosis factor and cancer. Nat Rev Cancer 9: 361-371, 2009.

3. Karin M and Greten FR: NF- $\kappa$ B: linking inflammation and immunity to cancer development and progression. Nat Rev Immunol 5: 749-759, 2005.

4. Luo JL, Kamata $\mathrm{H}$ and Karin $\mathrm{M}$ : IKK/NF- $\kappa \mathrm{B}$ signaling: balancing life and death - a new approach to cancer therapy. J Clin Invest 115: 2625-2632, 2005.

5. Thiery JP: Epithelial-mesenchymal transitions in tumour progression. Nat Rev Cancer 2: 442-454, 2002.

6. Huber MA, Kraut N and Beug H: Molecular requirements for epithelial-mesenchymal transition during tumor progression. Curr Opin Cell Biol 17: 548-558, 2005.

7. Kang Y and Massagué J: Epithelial-mesenchymal transitions: twist in development and metastasis. Cell 118: 277-279, 2004

8. Yu L, Lu S, Tian J, et al: TWIST expression in hypopharyngeal cancer and the mechanism of TWIST-induced promotion of metastasis. Oncol Rep 27: 416-422, 2012.

9. Yu L, Li HZ, Lu SM, et al: Down-regulation of TWIST decreases migration and invasion of laryngeal carcinoma Hep-2 cells by regulating the E-cadherin, $\mathrm{N}$-cadherin expression. J Cancer Res Clin Oncol 137: 1487-1493, 2011.

10. Wang H, Wang HS, Zhou BH, et al: Epithelial-mesenchymal transition (EMT) induced by TNF- $\alpha$ requires AKT/GSK-3 $\beta$-mediated stabilization of Snail in colorectal cancer. PLoS One 8: e56664, 2013.

11. Techasen A, Namwat N, Loilome $\mathrm{W}$, et al: Tumor necrosis factor- $\alpha(\mathrm{TNF}-\alpha)$ stimulates the epithelial-mesenchymal transition regulator Snail in cholangiocarcinoma. Med Oncol 29: 3083-3091, 2012.

12. Wu Y, Deng J, Rychahou PG, Qiu S, Evers BM and Zhou BP: Stabilization of Snail by NF- $\mathrm{KB}$ is required for inflammation-induced cell migration and invasion. Cancer Cell 15: 416-428, 2009.

13. Wu ST, Sun GH, Hsu CY, et al: Tumor necrosis factor- $\alpha$ induces epithelial-mesenchymal transition of renal cell carcinoma cells via a nuclear factor $\kappa \mathrm{B}$-independent mechanism. Exp Biol Med 236: 1022-1029, 2011.

14. Smith RB, Apostolakis LW, Karnell LH, et al: National Cancer Data Base report on osteosarcoma of the head and neck. Cancer 98: 1670-1680, 2003.

15. Lefebvre JL, Castelain B, De la Torre JC, Delobelle-Deroide A and Vankemmel B: Lymph node invasion in hypopharynx and lateral epilarynx carcinoma: a prognostic factor. Head Neck Surg 10: 14-18, 1987.

16. Eccles SA and Welch DR: Metastasis: recent discoveries and novel treatment strategies. Lancet 369: 1742-1757, 2007. 
17. Yu L, Li HZ, Lu SM, et al: Alteration in TWIST expression: possible role in paclitaxel-induced apoptosis in human laryngeal carcinoma Hep-2 cell line. Croat Med J 50: 536-542, 2009.

18. Bates RC and Mercurio AM: Tumor necrosis factor- $\alpha$ stimulates the epithelial-to-mesenchymal transition of human colonic organoids. Mol Biol Cell 14: 1790-1800, 2003.

19. Takahashi E, Nagano O, Ishimoto $\mathrm{T}$, et al: Tumor necrosis factor- $\alpha$ regulates transforming growth factor- $\beta$-dependent epithelial-mesenchymal transition by promoting hyaluronanCD44-moesin interaction. J Biol Chem 285: 4060-4073, 2010.

20. Balkwill F: Tumor necrosis factor or tumor promoting factor? Cytokine Growth Factor Rev 13: 135-141, 2002.

21. Lee SO, Lou W, Hou M, de Miguel F, Gerber L and Gao AC: Interleukin-6 promotes androgen-independent growth in LNCaP human prostate cancer cells. Clin Cancer Res 9: 370-376, 2003.

22. Yamauchi Y, Kohyama T, Takizawa H, et al: Tumor necrosis factor- $\alpha$ enhances both epithelial-mesenchymal transition and cell contraction induced in A549 human alveolar epithelial cells by transforming growth factor- $\beta 1$. Exp Lung Res 36 : $12-24,2010$

23. Drake JM, Strohbehn G, Bair TB, Moreland JG and Henry MD: ZEB1 enhances transendothelial migration and represses the epithelial phenotype of prostate cancer cells. Mol Biol Cell 20: 2207-2217, 2009
24. Yang J, Mani SA, Donaher JL, et al: Twist, a master regulator of morphogenesis, plays an essential role in tumor metastasis. Cell 117: 927-939, 2004

25. Peinado H, Olmeda D and Cano A: Snail, Zeb and bHLH factors in tumour progression: an alliance against the epithelial phenotype? Nat Rev Cancer 7: 415-428, 2007.

26. Li CW, Xia W, Huo L, et al: Epithelial-mesenchymal transition induced by $\mathrm{TNF}-\alpha$ requires NF- $\mathrm{BB}$-mediated transcriptional upregulation of Twist1. Cancer Res 72: 1290-1300, 2012.

27. Chua HL, Bhat-Nakshatri P, Clare SE, Morimiya A, Badve S and Nakshatri $\mathrm{H}$ : NF- $\kappa \mathrm{B}$ represses E-cadherin expression and enhances epithelial to mesenchymal transition of mammary epithelial cells: potential involvement of ZEB-1 and ZEB-2. Oncogene 26: 711-724, 2007.

28. Min C, Eddy SF, Sherr DH and Sonenshein GE: NF- $\kappa B$ and epithelial to mesenchymal transition of cancer. J Cell Biochem 104: 733-744, 2008.

29. Kaisho T, Takeda K, Tsujimura T, et al: IкB kinase $\alpha$ is essential for mature B cell development and function. J Exp Med 193: 417-426, 2001.

30. Storci G, Sansone P, Mari S, et al: TNFalpha up-regulates SLUG via the NF-kappaB/HIF1alpha axis, which imparts breast cancer cells with a stem cell-like phenotype. J Cell Physiol 225: 682-691, 2010 . 